\title{
Trend of cost and utilization of COPD medication in Korea
}

Jongmin Lee'

Jae Ha Lee'

Jee-Ae Kim²

Chin Kook Rhee'

'Division of Pulmonary, Allergy and Critical Care Medicine, Department of Internal Medicine, Seoul St Mary's Hospital, College of Medicine, The Catholic University of Korea, Seoul, ${ }^{2}$ Pharmaceutical Policy Evaluation Research Team, Research Institution, Health Insurance Review and Assessment Service, Wonju-si, Republic of Korea
Correspondence: Jee-Ae Kim

Pharmaceutical Policy Evaluation Research Team, Research Institution, Health Insurance Review and Assessment Service, 60 Hyeoksin-ro, Wonju-si 26465,

Gangwon-do, Republic of Korea

Email kimjeeae@gmail.com

Chin Kook Rhee

Division of Pulmonary, Allergy and Critical Care Medicine, Department of Internal Medicine, Seoul St Mary's Hospital, College of Medicine, The

Catholic University of Korea, 222

Banpodaero, Seochogu, Seoul 0659I,

Republic of Korea

Tel +82 222586067

Fax +82 25993589

Email chinkook@catholic.ac.kr
This article was published in the following Dove Press journal:

International Journal of COPD

19 December 2016

Number of times this article has been viewed

Background: There are only a few longitudinal studies regarding medical utilization and costs for patients with COPD. The purpose of this study was to analyze the trend of medical utilization and costs on a long-term basis.

Methods: Using the Korean Health Insurance Review and Assessment Service (HIRA) data from 2008 to 2013, COPD patients were identified. The trend of medical utilization and costs was also analyzed.

Results: The number of COPD patients increased by 13.9\% from 2008 to 2013. During the same period, the cost of COPD medication increased by $78.2 \%$. Methylxanthine and systemic beta agonists were most widely prescribed between 2008 and 2013. However, inhaled medications such as long-acting beta-2 agonist (LABA), long-acting muscarinic agonist, and inhaled corticosteroid plus LABA were dispensed to a relatively low proportion of patients with COPD. The number of patients who were prescribed inhaled medications increased gradually from 2008 to 2013 , while the number of patients prescribed systemic beta agonist and methylxanthine has decreased since 2010 .

Conclusion: This study shows that there is a large gap between the COPD guidelines and clinical practice in Korea. Training programs for primary care physicians on diagnosis and guideline-based treatment are needed to improve the management of COPD.

Keywords: pulmonary disease, chronic obstructive, drug prescriptions, medical utilization, medical cost

\section{Introduction}

COPD is characterized by an airflow limitation with a forced expiratory volume in 1 second/forced vital capacity ratio of $<70 \%$, which is not fully reversible. The worldwide prevalence of COPD is increasing, and the Global Burden of Disease Study has estimated that it will be the fourth leading cause of death in $2030 .{ }^{1}$ With increasing prevalence, the economic burden of COPD is also increasing. In 2010, the estimated cost of COPD in the USA was \$50 billion, which included \$20 billion of indirect costs and $\$ 30$ billion of direct health care expenditures. ${ }^{2}$ Although more studies have recently investigated the economic burden of COPD, existing data show remarkable variations due to differences in survey methods, diagnostic criteria, and analytic approaches. ${ }^{3}$ Though simple, inexpensive spirometers are now available for clinical practices, underrecognition and underdiagnosis of COPD affect the accuracy of data. ${ }^{4}$

Although some studies have reported the cost and utilization of medication for $\mathrm{COPD},{ }^{5}$ not many have reviewed these factors for an entire country. Moreover, only few longitudinal studies have followed the cases on a long-term basis.

Korea has a compulsory universal health insurance system that includes medical reimbursement records for the entire Korean population. The Korean Health Insurance Review and Assessment Service (HIRA) database has detailed information about 
diagnosis, health care use, and medication, and is thus a reliable source for nationwide epidemiological evaluations. ${ }^{6}$ The objective of this article is to analyze the cost and utilization of COPD medication in Korea using the HIRA database.

\section{Methods}

\section{Data sources}

We used the HIRA data from 2008 to 2013 to analyze trends in cost and utilization of COPD medication. All hospitals, clinics, public health centers, and pharmacies are registered with the Korean National Health Insurance (NHI). The health care service providers first file a claim with the NHI, after which the HIRA assesses the claim based on diagnostic codes and medical records.

\section{Patient selection}

An operational definition was used for extracting COPD patients from the HIRA database..$^{7-10}$ We searched for subjects with diagnosis of COPD based on the International Classification of Disease - Tenth Revision (ICD-10) codes and medications prescribed. COPD patients were defined as subjects who met all of the following criteria: 1) age $\geq 40$ years; 2 ) ICD- 10 codes for COPD or emphysema (J43.0x-J44.X, with the exception of J43.0 as primary or secondary [within fourth position] diagnosis); and 3) the use of more than one of the following COPD medications at least twice per year: long-acting muscarinic antagonist (LAMA), long-acting beta-2 agonist (LABA), inhaled corticosteroid (ICS) + LABA, short-acting muscarinic antagonist (SAMA), short-acting beta-2 agonist (SABA), SAMA + SABA, phosphodiesterase-4 (PDE-4) inhibitor, systemic beta agonist, or methylxanthine.

\section{Analysis}

The cost and utilization of COPD medication were analyzed from 2008 to 2013. Only COPD-related medications (ICS, ICS + LABA, LABA, LAMA, leukotriene receptor antagonist [LTRA], oral corticosteroid [OCS], PDE-4 inhibitor, SABA, SAMA, SABA + SAMA, methylxanthine, and systemic beta agonist) were included in the analysis. All costs are presented in US dollars (one US dollar $=1,144$ Korean won, as of 12 April 2016). The Ethics Committee of Seoul St Mary's Hospital approved the present study and waived the requirement for informed patient consent due to the retrospective nature of the study.

\section{Results}

\section{Changes in overall medical use during the past 6 years}

In Korea, the number of COPD patients increased by $13.9 \%$ from 184,059 to 209,579 since 2008 until 2013. The average number of prescribed medications for COPD also increased from 10.1 to 12.0 (Table 1). The total cost of COPD-related medication increased by $78.2 \%$ $(\$ 20,787,780)$. The cost of COPD medication per person increased from $\$ 138.4$ in 2008 to $\$ 216.6$, a $56.5 \%$ increase over 6 years. Table 2 shows the cost of medication prescribed for COPD per patient and its change. Table 3 shows the changes in the pattern of medication prescriptions for COPD from 2008 to 2013.

\section{Long-acting bronchodilators (LABA and LAMA)}

Indacaterol was approved for use in Korea in 2010. Before then, LABA was rarely prescribed. In 2008, LABA inhalers were dispensed to only $1.1 \%(2,084)$ of the COPD patients. In $2013,6.1 \%(12,843)$ of the Korean COPD patients were prescribed LABA, an $83.8 \%$ increase over 6 years (Figure 1). Prescriptions for LAMA increased gradually as well. In 2008, LAMA inhalers were dispensed to $26.2 \%(48,296)$ of COPD patients in Korea, and this increased to $37.3 \%(78,227)$ in 2013 (Figure 2). The cost of LAMA accounted for the largest proportion of the cost of COPD medication over 6 years. The total cost of LAMA increased from $\$ 9,738,800$ in 2008 to $\$ 18,766,800$ in 2013 , a $92.3 \%$ increase over the 6 years (Table 3).

\section{ICS}

In 2008, ICS-only inhalers were dispensed to $11.3 \%(20,756)$ of patients, and this increased gradually, but decreased after

Table I Number of COPD patients and prescriptions of each medication from 2008 to 2013

\begin{tabular}{lllllll}
\hline & $\mathbf{2 0 0 8}$ & $\mathbf{2 0 0 9}$ & $\mathbf{2 0 1 0}$ & $\mathbf{2 0 1 1}$ & $\mathbf{2 0 1 2}$ & $\mathbf{2 0 1 3}$ \\
\hline $\begin{array}{l}\text { Number of patients } \\
\text { Number of prescriptions }\end{array}$ & 184,059 & 180,334 & 211,148 & 217,624 & 224,889 & 209,579 \\
$\begin{array}{l}\text { per patient each year } \\
\text { Number of prescriptions for }\end{array}$ & 71.2 & 71.6 & 70.6 & 69.7 & 74.1 & 73.8 \\
COPD per patient each year & & 10.1 & 10.0 & 11.6 & 11.5 & 11.9 \\
\hline
\end{tabular}

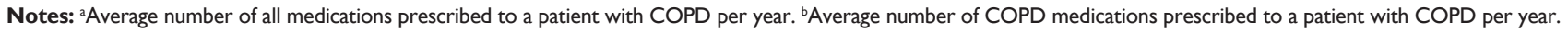


Table 2 Changes in the cost of prescribed medication for COPD per patient over the 6 years (all costs are in US dollars)

\begin{tabular}{lllllll}
\hline Medication & $\mathbf{2 0 0 8}$ & $\mathbf{2 0 0 9}$ & $\mathbf{2 0 1 0}$ & $\mathbf{2 0 I I}$ & $\mathbf{2 0 I \mathbf { 2 }}$ & $\mathbf{2 0 I 3}$ \\
\hline ICS & 33.5 & 34.7 & 34.6 & 34.4 & 33.2 & 32.3 \\
ICS + LABA & 182.9 & 191.5 & 194.8 & 198.3 & 201 & 199 \\
LABA & 11.7 & 8.7 & 6.2 & 5.7 & $1 \mathrm{I}$ & 73.9 \\
LAMA & 202.6 & 216.2 & 230.5 & 237.2 & 238 & 241 \\
LTRA & 89.2 & 87.7 & 125.1 & 127 & 102.1 & 86.5 \\
OCS & 1.8 & 1.9 & 4 & 3.8 & 3.2 & 3 \\
PDE-4 inhibitor & 0 & 0 & 0 & 0 & 0 & 92.1 \\
SABA & 11.8 & 12.4 & 12.2 & 13.5 & 12.1 & 12.1 \\
SABA + SAMA & 37.6 & 39.5 & 37.7 & 17.2 & 9.2 & 10.1 \\
SAMA & 19.4 & 19.6 & 17.9 & 17.5 & 15.5 & 15.1 \\
Methylxanthine & 23.1 & 27.3 & 25 & 26.3 & 22.4 & 20.2 \\
Systemic beta agonist & 19.1 & 20.7 & 23.2 & 23.8 & 21.2 & 20.8 \\
\hline
\end{tabular}

Abbreviations: ICS, inhaled corticosteroid; LABA, long-acting beta-2 agonist; LAMA, long-acting muscarinic antagonist; LTRA, leukotriene receptor antagonist; OCS, oral corticosteroid; PDE-4, phosphodiesterase-4; SABA, short-acting beta-2 agonist; SAMA, short-acting muscarinic antagonist.

2012 (Figure 3). In parallel, the total cost of ICS-only inhalers increased from $\$ 692,500$ in 2009 to $\$ 860,400$ in 2012 , but decreased to $\$ 774,300$ in 2013 .

\section{ICS plus LABA}

In $2008,27.4 \%(50,500)$ of patients with COPD were dispensed ICS + LABA, and this increased to $32.3 \%(72,727)$ in 2012, but decreased from 2012 to 2013 (Figure 4). The total cost of ICS + LABA gradually increased from 2008 to 2012, but decreased from $\$ 14,550,700$ in 2012 to $\$ 14,027,000$ in 2013 (Table 3).

\section{PDE-4 inhibitor}

Roflumilast is the only PDE-4 inhibitor approved in Korea. In 2013, it was approved for reimbursement in Korea as an add-on therapy for COPD. In 2013, 1.5\% $(3,309)$ of the patients with COPD were prescribed roflumilast at a total cost of $\$ 278,400$ (Table 3 and Figure 5).

\section{LTRA}

LTRA is a well-known medication for asthma. Although LTRA is not recommended for patients with COPD in guideline, it is widely used for patients with asthma-COPD overlap syndrome. ${ }^{10,11}$ In 2013, $26.7 \%(60,116)$ of patients with COPD were dispensed LTRA, an increase from $1.2 \%$ $(2,278)$ in 2008 (Figure 6).

\section{OCS}

Among the people who were given any medications indicated for the treatment of COPD in 2013, 28.6\% had been dispensed OCS, an increase from $22.5 \%$ in 2008 (Figure 7). As shown in Table 3, the total cost of OCS increased gradually from $\$ 75,700$ in 2008 to $\$ 229,680$ in 2011, but decreased after 2011 to $\$ 176,600$.

\section{Short-acting bronchodilators}

In 2008, 32.9\% of the Korean COPD patients were prescribed SABA, and the proportion of COPD patients using SABA has remained steady since 2008 (Figure 8). The total cost of SABA increased gradually from $\$ 712,500$ in 2008 to $\$ 871,700$ in 2011, but has decreased slightly since 2012 (Table 3). In 2012, $12.6 \%$ of patients with COPD were prescribed an SAMA, a gradual decrease from $17.2 \%$ in 2008 (Figure 9). The total cost of SAMA also decreased from $\$ 609,900$ in 2008 to $\$ 399,300$ in 2013. In 2008, combined SABA + SAMA was prescribed to $27 \%$ of the patients with COPD in Korea; however, the number of SABA + SAMA prescriptions decreased markedly from 2011 to 2013 as the manufacture of SABA + SAMA was discontinued in Korea since 2011 (Figure 10).

Table 3 Change in the number of prescriptions and cost over the 6 years (all costs are in US\$I,000)

\begin{tabular}{|c|c|c|c|c|c|c|c|c|c|c|c|c|}
\hline \multirow[t]{2}{*}{ Medication } & \multicolumn{2}{|l|}{2008} & \multicolumn{2}{|l|}{2009} & \multicolumn{2}{|l|}{2010} & \multicolumn{2}{|l|}{2011} & \multicolumn{2}{|l|}{2012} & \multicolumn{2}{|l|}{2013} \\
\hline & $\mathbf{n}$ & Cost & $\mathbf{n}$ & Cost & $\mathbf{n}$ & Cost & $\mathbf{n}$ & Cost & $\mathbf{n}$ & Cost & $\mathbf{n}$ & Cost \\
\hline ICS & 20,756 & 692.5 & 20,854 & 719.5 & 21,693 & 746.5 & 22,660 & 776.9 & 26,033 & 860.4 & 24,081 & 774.3 \\
\hline ICS + LABA & 50,500 & $9,191.6$ & 54,354 & $10,358.2$ & 60,519 & II,732.0 & 67,883 & 13,399.7 & 72,727 & $14,550.7$ & 70,820 & $14,027.0$ \\
\hline LABA & 2,084 & 24.4 & 2,515 & 21.8 & 2,631 & 16.5 & 2,842 & 15.7 & 4,058 & 44.4 & 12,843 & 944.8 \\
\hline LAMA & 48,296 & $9,738.8$ & 55,377 & ||$, 9 \mid 4.7$ & 63,587 & |4,590.8 & 70,346 & $16,609.2$ & 76,931 & $18,225.6$ & 78,227 & $18,766.8$ \\
\hline LTRA & 2,278 & 202.7 & $4,2 \mid 4$ & 368.0 & 39,689 & $4,941.6$ & 47,160 & $5,959.5$ & 58,597 & $5,956.0$ & 60,116 & $5,173.0$ \\
\hline OCS & 41,425 & 75.7 & 38,794 & 74.8 & 57,548 & 228.8 & 60,368 & 229.68 & 65,033 & 207.9 & 59,913 & 176.6 \\
\hline PDE-4 inhibitor & 0 & 0 & 0 & 0 & 0 & 0 & 0 & 0 & 0 & 0 & 3,039 & 278.4 \\
\hline SABA & 60,590 & 712.5 & 58,087 & 717.8 & 61,180 & 743.0 & 64,830 & 871.7 & 70,347 & 846.5 & 66,223 & 796.1 \\
\hline SABA + SAMA & 5,012 & 187.1 & 4,449 & 174.9 & 4,356 & 163.6 & 1,269 & 21.75 & 23 & 0 & 6 & 0 \\
\hline SAMA & 31,597 & 609.9 & 29,481 & 574.2 & 26,656 & 473.3 & 24,334 & 422.8 & 28,253 & 435.9 & 26,482 & 399.3 \\
\hline Methylxanthine & 97,448 & $2,235.9$ & 92,125 & $2,503.9$ & 156,730 & $3,898.5$ & 155,936 & $4,089.0$ & $|5|, 263$ & $3,373.0$ & 132,922 & $2,674.4$ \\
\hline Systemic beta agonist & 94,715 & $1,800.9$ & 84,693 & $\mathrm{I}, 744.4$ & 87,256 & $2,016.7$ & 85,106 & $2,016.7$ & 80,847 & I,703.5 & 66,670 & 1,379.8 \\
\hline
\end{tabular}

Abbreviations: ICS, inhaled corticosteroid; LABA, long-acting beta-2 agonist; LAMA, long-acting muscarinic antagonist; LTRA, leukotriene receptor antagonist; OCS, oral corticosteroid; PDE-4, phosphodiesterase-4; SABA, short-acting beta-2 agonist; SAMA, short-acting muscarinic antagonist. 


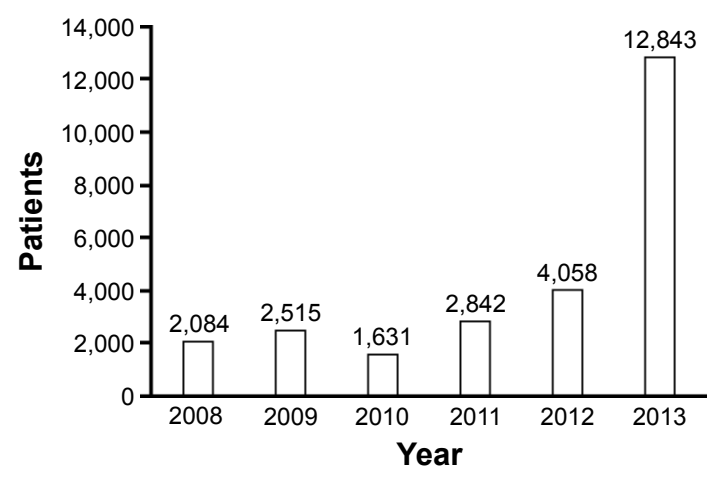

Figure I Change in the number of LABA prescriptions over the 6 years. Abbreviation: LABA, long-acting beta-2 agonist.

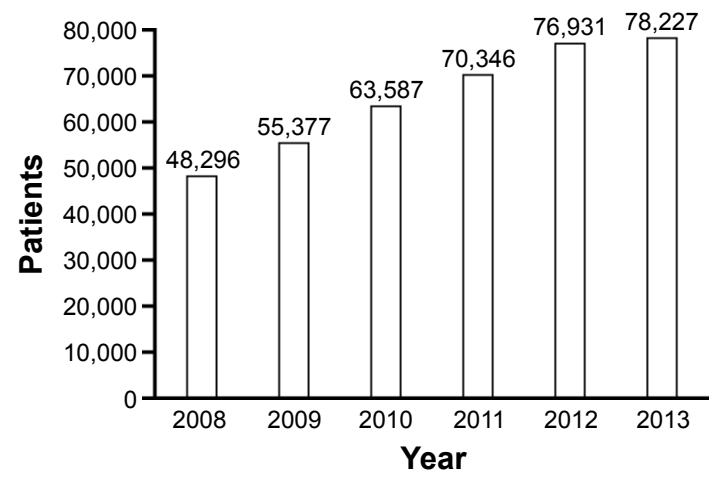

Figure 2 Change in the number of LAMA prescriptions over the 6 years. Abbreviation: LAMA, long-acting muscarinic antagonist.

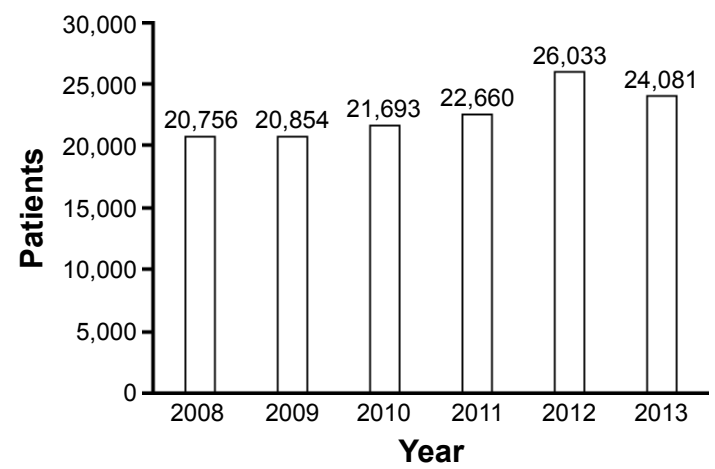

Figure 3 Change in the number of ICS prescriptions over the 6 years. Abbreviation: ICS, inhaled corticosteroid.

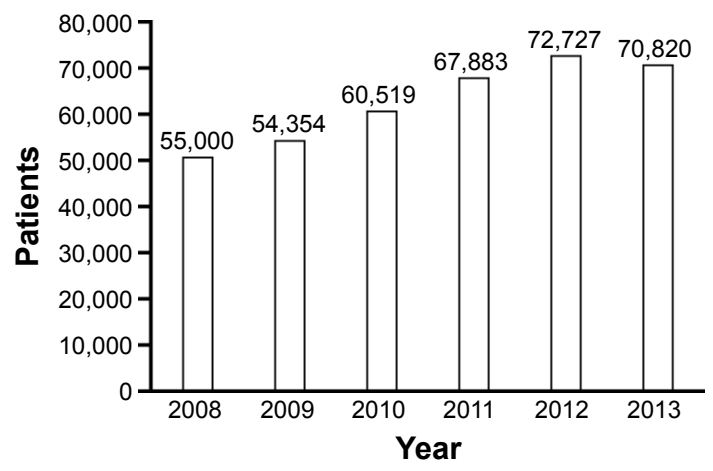

Figure 4 Change in the number of ICS + LABA prescriptions over the 6 years. Abbreviations: ICS, inhaled corticosteroid; LABA, long-acting beta- 2 agonist.

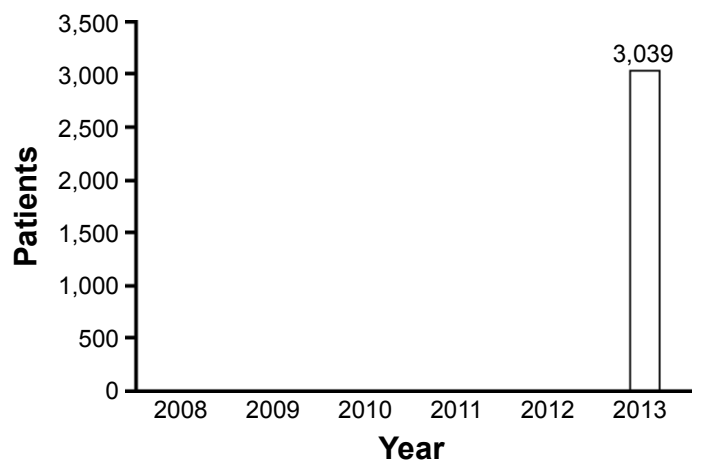

Figure 5 Change in the number of PDE-4 inhibitor prescriptions over the 6 years. Abbreviation: PDE-4, phosphodiesterase-4.

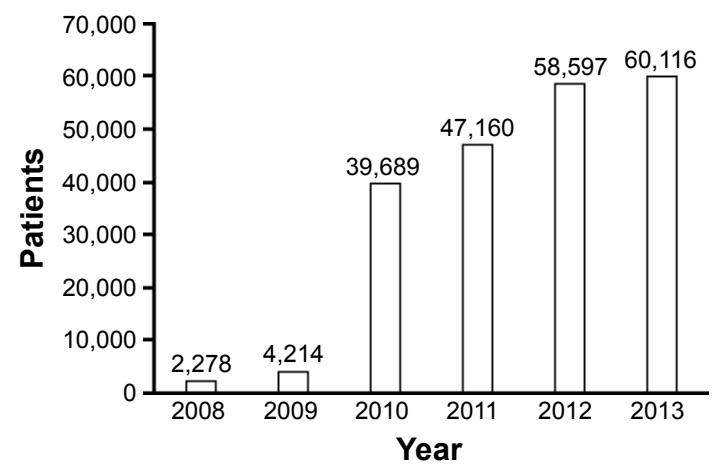

Figure 6 Change in the number of LTRA prescriptions over the 6 years. Abbreviation: LTRA, leukotriene receptor antagonist.

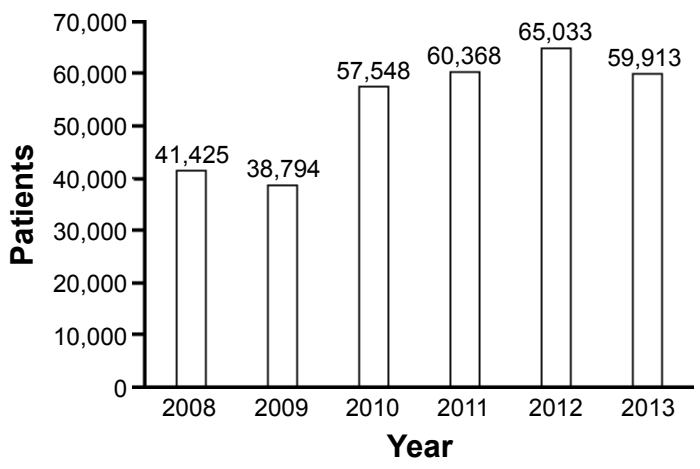

Figure 7 Change in the number of OCS prescriptions over the 6 years. Abbreviation: OCS, oral corticosteroid.

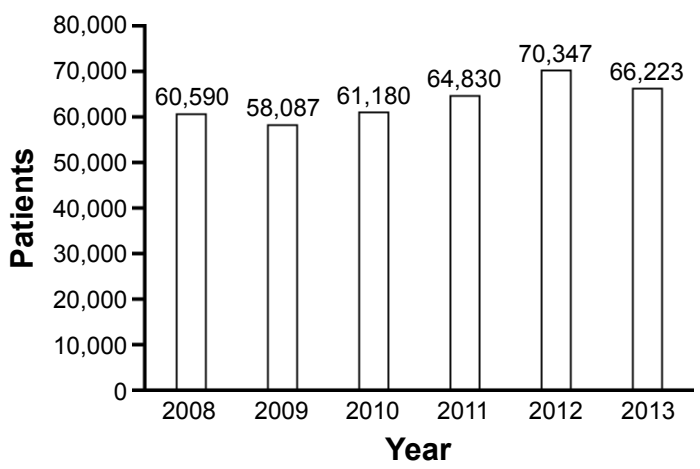

Figure 8 Change in the number of SABA prescriptions over the 6 years. Abbreviation: SABA, short-acting beta-2 agonist. 


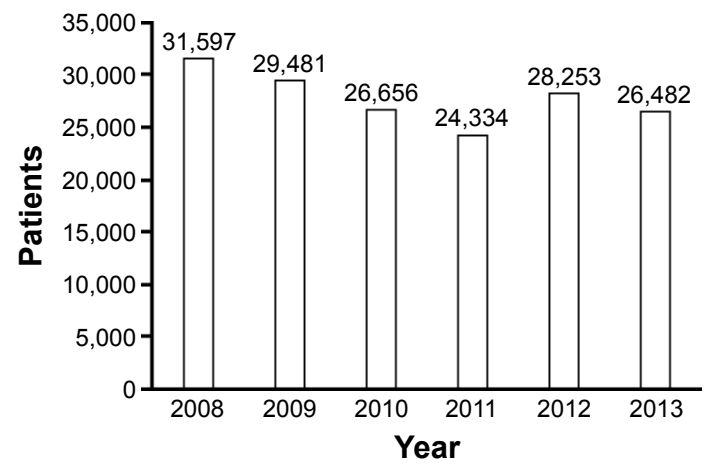

Figure 9 Change in the number of SAMA prescriptions over the 6 years. Abbreviation: SAMA, short-acting muscarinic antagonist.

\section{Methylxanthine}

Methylxanthine has been the most widely prescribed medication for the management of COPD in Korea between 2008 and 2013 . A total of $52.9 \%$ of patients with COPD were prescribed methylxanthine in 2008 , and the proportion increased to $74.2 \%$ in 2010 . In 2013, methylxanthine was dispensed to $63.4 \%$ of patients with COPD in Korea (Figure 11). The total cost of methylxanthine increased from $\$ 2,235,900$ in 2008 to $\$ 4,089,000$ in 2011 and then decreased to $\$ 2,674,400$ in 2013 (Table 3).

\section{Systemic beta agonist}

Although systemic beta agonist is not recommended for the treatment of COPD, it was prescribed to $51.5 \%$ of patients with COPD in 2008. As shown in Figure 12, the proportion of patients who were prescribed systemic beta agonist decreased to $31.8 \%$ in 2013 . The total cost of systemic beta agonist also decreased from $\$ 1,800,900$ in 2008 to $\$ 1,379,800$ in 2013 (Table 3).

\section{Discussion}

In this nationwide study, we used Korean HIRA data to analyze cost and utilization of COPD medication in Korea.

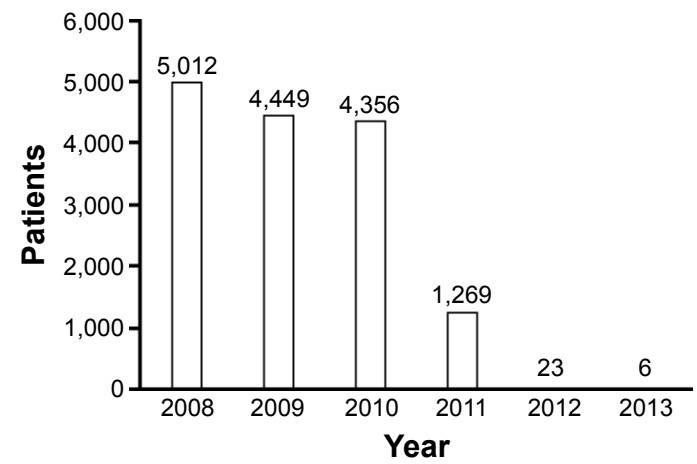

Figure 10 Change in the number of SABA + SAMA prescriptions over the 6 years. Abbreviations: SABA, short-acting beta-2 agonist; SAMA, short-acting muscarinic antagonist.

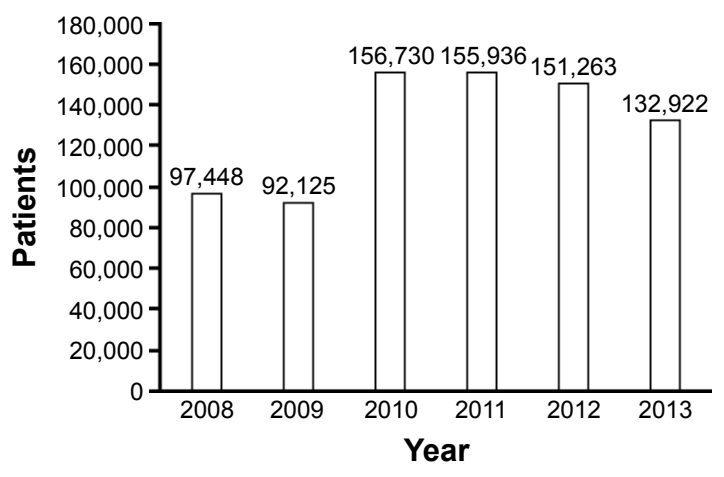

Figure I I Change in the number of methylxanthine prescriptions over the 6 years.

The number of COPD patients increased by $22.2 \%$ from 2008 to 2012. This increase is partly related to an increase in the elderly population in Korea. ${ }^{12}$ Improved physician understanding of COPD may have contributed to the increase in the number of COPD patients until 2012. During the study period, the cost of COPD medication increased by $78.2 \%$, mainly due to increase in prescription rates for LAMA and ICS + LABA, which are more expensive than other COPD medications.

This study found that oral medications such as methylxanthine and systemic beta agonist were widely prescribed, while inhaled medications such as LABA, LAMA, and ICS + LABA were dispensed to a relatively low proportion of patients with COPD. Although the use of methylxanthine is recommended when the symptom of breathlessness remains despite the use of inhaled bronchodilators, ${ }^{13}$ it is not a major medication in the treatment of COPD. However, methylxanthine was the most commonly prescribed COPD medication over 6 years in Korea. This reflects the poor compliance to current treatment guidelines for COPD in real clinical practice. There are several possible explanations for this discrepancy between the COPD guideline and real practice. One study reported that primary care physicians (PCPs) in Korea preferred oral to inhaled medication for

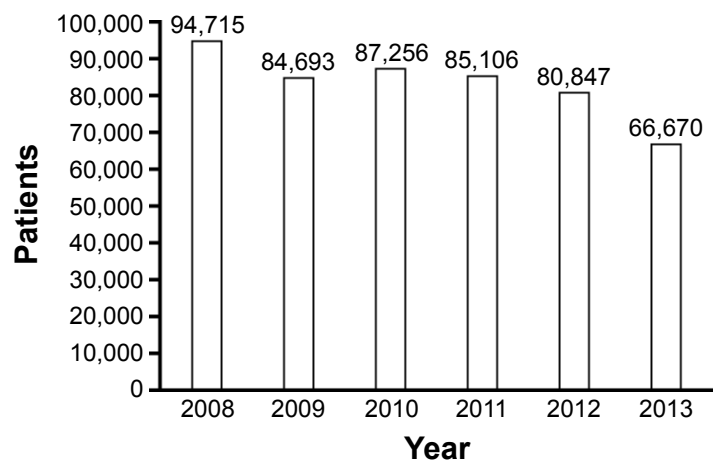

Figure 12 Change in the number of systemic beta agonist prescriptions over the 6 years. 
both stable COPD and acutely exacerbated COPD. ${ }^{14}$ It is mainly because the reimbursement criteria for inhaler medication for COPD are based on the spirometry results. Therefore, without spirometry results, it is difficult to prescribe inhalers to COPD patients in Korea. Although a diagnosis of COPD by spirometry is essential for prescribing inhaled medication in Korea, the use of spirometry by PCPs was low. ${ }^{14}$ It is also possible that PCPs felt constrained by the amount of time it would take to teach correct use of inhaled medications in a primary care setting, although education is necessary to ensure the effectiveness of inhaled medications.

Nevertheless, the results show that there has been a steady improvement in this discrepancy. The number of patients who were prescribed inhalers increased between 2008 and 2013, while the number of patients prescribed systemic beta agonist and methylxanthine has decreased since 2010.

There are some limitations to this study. First, no pulmonary function test results were available. Therefore, the enrolled patients did not have proven diagnoses of COPD, and the severity of COPD could not be assessed based on spirometry. Second, since the data analyzed were based on the pharmacy records of dispensed prescriptions, adherence to the prescribed medication was not measured in this study. Non-adherence to COPD therapy is widespread and a significant risk factor for morbidity and mortality. ${ }^{15}$ Underuse of medications is common, with reports that up to $49.4 \%$ of COPD patients are not taking their medications as prescribed. ${ }^{16-18}$ A further study with more focus on adherence is therefore recommended. Third, data on smoking history and environmental or occupational exposure were not available, so the cause of the COPD is unknown in the patients enrolled in this study.

\section{Conclusion}

Analysis of the Korean NHI database shows that there is a large gap between the COPD guidelines and clinical practice in Korea. The problems we have highlighted include evidence of substantial over- and underuse of certain classes of medications when compared with the COPD guidelines for the appropriate use of these medications. These findings are important in terms of both the missed opportunities for improved disease control and the additional cost burden and risk of adverse effects imposed by the incorrect use of medications. Although there might be various reasons for the deviation between the guidelines and the clinical practice, they could not be analyzed in this study due to the limitation of nature of claim data. Further investigation into the factors that could affect this discrepancy will be needed.

\section{Acknowledgment}

This study was conducted as a part of the project "The trend of medication utilization and adherence to medication among patients with chronic conditions - case of COPD" by HIRA.

\section{Disclosure}

CKR received consulting/lecture fees from MSD, AstraZeneca, Novartis, GSK, Takeda, Mundipharma, Sandoz, Boehringer-Ingelheim, and Teva-Handok. The other authors report no conflicts of interest in this work.

\section{References}

1. Mathers CD, Loncar D. Projections of global mortality and burden of disease from 2002 to 2030. PLoS Med. 2006;3(11):e442.

2. Guarascio AJ, Ray SM, Finch CK, Self TH. The clinical and economic burden of chronic obstructive pulmonary disease in the USA. Clinicoecon Outcomes Res. 2013;5:235-245.

3. Halbert RJ, Natoli JL, Gano A, Badamgarav E, Buist AS, Mannino DM. Global burden of COPD: systematic review and meta-analysis. Eur Respir J. 2006;28(3):523-532.

4. Pena VS, Miravitlles M, Gabriel R, et al. Geographic variations in prevalence and underdiagnosis of COPD: results of the IBERPOC multicentre epidemiological study. Chest. 2000;118(4):981-989.

5. Pauwels RA, Rabe KF. Burden and clinical features of chronic obstructive pulmonary disease (COPD). Lancet. 2004;364(9434):613-620.

6. Lee YH, Yoon SJ, Kim EJ, Kim YA, Seo HY, Oh IH. Economic burden of asthma in Korea. Allergy Asthma Proc. 2011;32(6):35-40.

7. Kim C, Yoo KH, Rhee CK, et al. Health care use and economic burden of patients with diagnosed chronic obstructive pulmonary disease in Korea. Int J Tuberc Lung Dis. 2014;18(6):737-743.

8. Kim J, Lee JH, Kim Y, et al. Association between chronic obstructive pulmonary disease and gastroesophageal reflux disease: a national cross-sectional cohort study. BMC Pulm Med. 2013;13:51.

9. Kim J, Rhee CK, Yoo KH, et al. The health care burden of high grade chronic obstructive pulmonary disease in Korea: analysis of the Korean Health Insurance Review and Assessment Service data. Int J Chron Obstruct Pulmon Dis. 2013;8:561-568.

10. Rhee CK, Yoon HK, Yoo KH, et al. Medical utilization and cost in patients with overlap syndrome of chronic obstructive pulmonary disease and asthma. COPD. 2014;11(2):163-170.

11. Rhee CK. Phenotype of asthma-chronic obstructive pulmonary disease overlap syndrome. Korean J Intern Med. 2015;30(4):443-449.

12. South Korea: Age structure between 2004 and 2014. Available from: https://www.statista.com/statistics/242558/age-distribution-in-southkorea/. Accessed October 31, 2016.

13. Vestbo J, Hurd SS, Agusti AG, et al. Global strategy for the diagnosis, management, and prevention of chronic obstructive pulmonary disease: GOLD executive summary. Am J Respir Crit Care Med. 2013; 187(4):347-365.

14. Park MJ, Choi CW, Kim SJ, et al. Survey of COPD management among the primary care physicians in Korea. Tuberc Respir Dis. 2008; 64(2):109-124.

15. Cochrane GM. Therapeutic compliance in asthma; its magnitude and implications. Eur Respir J. 1992;5(1):122-124. 
16. James PN, Anderson JB, Prior JG, White JP, Henry JA, Cochrane GM. Patterns of drug taking in patients with chronic airflow obstruction. Postgrad Med J. 1985;61(711):7-10.

17. Corden ZM, Bosley CM, Rees PJ, Cochrane GM. Home nebulized therapy for patients with COPD: patient compliance with treatment and its relation to quality of life. Chest. 1997;112(5):1278-1282.
18. Turner J, Wright E, Mendella L, Anthonisen N. Predictors of patient adherence to long-term home nebulizer therapy for COPD. The IPPB Study Group. Intermittent Positive Pressure Breathing. Chest. 1995; 108(2):394-400.

International Journal of COPD

\section{Publish your work in this journal}

The International Journal of COPD is an international, peer-reviewed journal of therapeutics and pharmacology focusing on concise rapid reporting of clinical studies and reviews in COPD. Special focus is given to the pathophysiological processes underlying the disease, intervention programs, patient focused education, and self management protocols.
Dovepress

This journal is indexed on PubMed Central, MedLine and CAS. The manuscript management system is completely online and includes a very quick and fair peer-review system, which is all easy to use. Visit http://www.dovepress.com/testimonials.php to read real quotes from published authors.

Submit your manuscript here: http://www.dovepress.com/international-journal-of-chronic-obstructive-pulmonary-disease-journal 